\title{
Exploration and Practice of Training Excellent Engineers of Traffic Engineering via School-enterprise Cooperation
}

\author{
Ya-ping ZHANG ${ }^{1,{ }^{*}}$, Yu-yang ZHAO ${ }^{2}$, Li-jun LUO ${ }^{3}$, Guo-zhu \\ CHENG $^{1}$, Yan-li MA ${ }^{1}$, Shao-wu CHENG ${ }^{1}$ and Li-hua LIU ${ }^{4}$ \\ ${ }^{1}$ School of Transportation Science and Engineering, Harbin Institute of Technology, \\ Harbin 150090, Heilongjiang, China \\ ${ }^{2}$ School of Automobile and Traffic Engineering, Heilongjiang Institute of Technology, \\ Harbin 150050, Heilongjiang, China \\ ${ }^{3}$ School of Automobile, Harbin Institute of Technology, Weihai 264209, Shandong, \\ China \\ ${ }^{4}$ School of Transportation Engineering, Henan University of Urban Construction, \\ Pingdingshan 467036, Henan, China \\ *Corresponding author Email: zxlt0905@163.com
}

Keywords: Chinese higher education, School-enterprise cooperation, Transportation engineering, Excellent engineer training program.

Abstract. Analyzed domestic and foreign education situation and development trend in excellent engineers training, and explained the significance and necessity of exploration and practice of traffic engineering excellent engineers training program. Combined with the actual situation of Chinese higher education, we explored ways, teaching methods, training programs and practical results to traffic engineering excellence engineers training program.

\section{Introduction}

With the acceleration of urbanization and technological advances, increasing Chinese families have the ability to choose the car as a means of transport. Thus, it leads to rapidly rising of urban vehicle population, which caused the city traffic problems: traffic congestion, energy consumption, environmental pollution, traffic safety and other diehard, and these produce countless losses.

Faced with such a severe traffic problem, Chinese colleges and universities are obliged to cultivate talents who adapt for traffic economic growth to meet the needs of the community, have outstanding comprehensive ability, are able to solve the traffic problems of practical application-oriented comprehensive traffic engineering. Currently in China, professional training program of Traffic Engineering in Colleges emphasizes teaching theory, while it has large gap between theory and practice hours, which leads to a lack of practical experience and comprehensive ability for students [1]. Practice teaching is an important teaching step for developing integrated application-oriented talents so that the education mode needs be reformed and the practice teaching step needs be innovated.

In the 21 st century, both technological advances and economic competition are fiercer than ever. Community has increasing demanding of composite and application-oriented talents. Training of practical ability cannot be completed without the participation of enterprises. School-enterprise cooperation, a combination of produce, education and research is the inevitable choice for adapting to the economic 
and social development, acquiring educational resources and seeking coordinated development of social objectives [2]. School-enterprise cooperation education is a full cooperation between schools and businesses and a win-win mechanism in the whole process of education.

China is in the process of industrialization medium term. Faced with the urgent requirements of development of China's economic restructuring and upgrading to enhance the international competitiveness, we need train all kinds of engineering and technical personnel who have superior innovation ability and ability of adapting to the needs of China's economic and social development. This also is the inevitable choice to enhance our core competitiveness, build an innovative country and take a new road to industrialization. Thus, Ministry of Education of China decided to implement the "excellent engineer training program". As science and technology advancing, particularly the development of information technology, network technology and computer technology, economic structure and social structure are undergoing profound changes. The knowledge economy and the network information begin to take shape. To meet the challenges of the times and train talents who can adapt to the social needs of the 21st century, higher education must reform the existing training model, and carry out the exploration and practice of traffic engineering "excellent engineer". This has important practical significance and great value to train a number of engineering and technical personnel who can adapt transport market and are welcomed by the community.

\section{Domestic and International Research Status and Trends on Training Excellent Engineers}

Currently, culture of engineers can be divided into two modes internationally. Firstly, the Washington Agreement Members mode, which is represented by the United States, is a mode that students in the school are educated with engineering basic knowledge emphatically. Vocational aspects of education are provided by the society after graduation, and these students can become engineers through the dedicated and professional certification examination. Second, continental Europe national models, which are represented by Germany and France, both students in the school complete the basic engineers training and they not only get the diploma and degree, but also the professional qualification [3]. In either mode, the engineer culture is inseparable from the participation and support of enterprises, and companies need accept the students to participate engineer training.

American universities and enterprises found "American Universities-Corporate Committee" to guide business managers and technical experts into college classrooms and laboratories. And universities train professional personnel energetically according to business requirements. The objective of this "technical preparation system" mode is to improve the skills of relevant personnel to meet the challenges of high-tech; integrate school-based learning and work-based learning; improve students' ability to solve problems through the participation and cooperation of enterprises; strengthen cooperation between school teachers and enterprises and joint plan courses; extend term so that students can learn skills by youth apprenticeships and other work-based learning approach [4].

"Dual System" Education in Germany is a form of Business and Education Cooperation mode which is a Vocational and Technical Education based on combining theory and practice [5]. Its characteristics are closely integrated with production; 
enterprise wide participation; interchange of the various types of education form; separation of training and assessment phase.

In 1984, France established "Education-Enterprises line" to promote the relationship between business and universities. From concept updating to the institutional innovation, it formed a government-business-school integrated operation mechanism [6]. After the integration of resources, education and the local economy were closely linked and embarked on a complementary benefit and common development of diversified educational track.

Britain's "sandwich" cooperative education mode widely used the form of sandwich in the way of curriculum. This course forms strengthen contacts and cooperation between industry and the education sector [7]. In addition, there are Japan's "industry, academia and government cooperation" mode, South Korea's school-enterprise contract "Order" training model, Australia's TAFE mode etc. [8].

After decades of careful exploration and practice, our school-enterprise cooperation in many colleges and universities received a significant effect. Schools and businesses have been able to take advantage of two different environments and educational resources to use the way of combining classroom teaching and students practical work. In practice, however, there are still many problems. It is still at the preliminary stage to explore appropriate way to train application-oriented talents and the awareness of participating in personnel training is weak. These mainly reflected in: firstly, instability of school-enterprise cooperation relationship; secondly, a lower proportion of school-enterprise cooperation in higher education institutions in the implementation; thirdly, what enterprises need are those advanced technology applied talents who can be employed directly, while lacking of enthusiasm to accept student internships [9].

Compared with United States and Europe countries, our current Engineering Personnel Training Mode tends to "scientific". This mainly reflected in these respects: emphasis on theory, the classroom education, profound knowledge, while contempt for practice, extracurricular and comprehensive knowledge. Thus, these "talents" under this education mode cannot adapt the sectors of society.

Deepening the reform of engineering personnel training mode, which has caused great concern in the tertiary education sector, needs to regard the needs of society as the guide, practical engineering as the background and engineering technology as the main line. Both American and European universities engineers training pattern do not meet the expectations of Chinese society and China higher education. Thus, the effective way is exploring "excellent engineer" with our own characteristics according to China's national conditions. And this asks us to reform from the target, quality specifications, training programs, curriculum content, teaching and training methods [10].

\section{Exploration and Practice of Training Excellent Engineers of Traffic Engineering}

\section{Exploration and Practice}

In recent years, on the basis of sufficient research, we implemented traffic engineering "excellent engineer training program" step by step, and carried out some useful exploration and practice.

(1) Designed the school-enterprise cooperation practicing teaching system and developed evaluation criteria of traffic engineering "excellent engineer training program" referring to international standards. 
(2) Selected and determined enterprises to fulfill the joint training program. Designated the following powerful and senior enterprises and institutes as the joint training program support units, including Jinan Urban Construction Group, Guangdong Tong Wang Technology Co., Ltd., Shenzhen Municipal Design and Research Institute, Tianjin Urban Construction Design Institute, Beijing Logistic Research Institute of China Transportation Association, Traffic Planning and Design Institute of the Ministry of Construction, Shanghai Rail Transit Co., Ltd. Aimed to achieve an integration excellent engineer training mode in production practice, graduation design and employment.

(3) Signed the joint training agreement with the enterprises. Focus on practical training. The enterprises enjoy priority recruitment authority, which mobiles the initiative of enterprises in participating the joint training program.

(4) Assessment and evaluation of the joint training program. We built the evaluation criteria facing to engineering ability, which means focusing on students' understanding of theoretical knowledge, and the analysis, comprehension and practical ability of knowledge at the same time.

(5) Took full advantage of international engineering education resources, adopted a "going out and inviting in" strategy. Based on the 985 engineering discipline investment, HIT-UIUC traffic engineering overseas partner base, and HIT-Washington University International Joint Laboratory Project in advanced transportation technology, we established education partnerships with University of Illinois at Urbana-Champaign, University of Washington, Northwestern University and other world famous universities by recruiting overseas experts and scholars giving lecture and building an international network video conference system. We achieved a real-time remote academic activity and remote access to academic resources, which open an under graduation education international cooperation mode in traffic engineering.

(6) Employed domestic enterprises senior technical experts as part-time professor, launched a series of lectures on traffic engineering problems, in order to student professional interests, expand professional horizons.

(7) Deployed professional instructors to undergraduate freshmen since their first day in school. Conducted face to face forum with the dean. Guided their life planning and career planning by conducting extensive communication with students.

(8) Arranged traffic engineering senior students to do graduation internships in Beijing, Shanghai, Dalian, Shenzhen, Hong Kong and other international metropolis by studying development overview in modern metropolitan transportation planning, design, construction, management and control field. Students were encouraged to do graduation design in their internships on relevant subjects, which enables students to adapt society, change their roles and find career location. Achieved a coordinated process of graduation internship, graduation design and job employment.

In addition, we carried out teaching and research project approval, practical education reform and teaching and research reform forum in terms of the "excellent engineer training program". In October, 2010, Harbin Institute of Technology School of Transportation Science and Engineering and Jinan Urban Construction Group signed an agreement to set up "Harbin Institute of Technology-Jinan Urban Construction Group joint training base", jointly constructed school-enterprise education and research and production base, and established Jinan Urban Construction Group Education Fund to reward outstanding undergraduate. In 2013, signed a school-enterprise joint training agreement with Liaoning Beisida Transportation Technology Development Co., Ltd. At the same time, signed school-enterprise cooperation frame agreement with Guangdong 
Tong Wang Technology Co., Ltd. In February 2011 and February 2013, with the support and assistance of Alumni Association in Shenzhen, Harbin Institute of Technology traffic engineering graduation internships proceeded smoothly in Shenzhen and Hong Kong. Graduates got deeper understanding of the modern city transport development patterns and trends, learnt the differences between north and south cities in traffic construction characteristics and style, and broadened their horizon in engineering area.

\section{Practical Results}

Harbin Institute of Technology is one of the first approved pilots on the "excellent engineer training program" by the Ministry of Education, China. We made the following practical results through years of exploration.

(1) In 2012, HIT Traffic Engineering got approved to be Heilongjiang key undergraduate major, China.

(2) In 2014, HIT Traffic Engineering passed the International Engineering Education Accreditation of the Ministry of Education, China.

(3) From 2013 to 2015, HIT Traffic Engineering students won one first prize, two second prize, two third prizes in the past three National Transportation Technology Competitions, China.

(4) From 2013 to 2015, HIT Traffic Engineering students won two second prize, two third prizes in transportation design competition hold by Liaoning Beisida Transportation Technology Development Co., Ltd, China.

\section{Conclusions}

Excellent engineer training program is a long and arduous task of universities engineering talents education. We made reform and innovation on traffic engineering practical teaching system, combined with the excellence engineer training program of the Ministry of Education, for purpose to improve the quality of teaching and students' practical ability and innovation. We integrated teaching content, reform practical teaching methods, proposed new school-enterprise cooperation pattern for cultivating applied engineering talents. The study objects were Traffic Engineering undergraduates, students and teachers of domestic joint universities are directly benefited. Through the implementation of the excellence engineer training program, traffic engineering undergraduate education quality and level have made great progress and have improved significantly.

\section{Acknowledgements}

This work were supported by the $12^{\text {th }}$ Five-year Plan key project fund of higher education science and research by Heilongjiang Association of Higher Education,China and teaching reform project fund by Education Department of Heilongjiang Province, China (Project HGJXHB1110298 and JG2012010169).

\section{References}

[1] A.F. Zhang, X.F. Liu. Reflection on the Implementation of "A plan for Educating and Training Out-standing Engineers", Research in Higher Education of Engineering, 2010, pp. 56-59. 
[2] J. Lin. Engineer Classification and Engineering Talent Training, Tsinghua Journal of Education, 2010, pp. 51-60.

[3] B, Diana, C.F. Monica, S. Mohit. A Project-Based Approach Professional Skills Training in an Undergraduate Engineering Curriculum, International Journal of Engineering Education, 2015, pp. 425-433.

[4] C.H. Lu. Differences in University Engineering Education between China and USA, International Conference on Psychology, Management and Social Science (PMSS 2013), 2013, 249-252.

[5] S. Takashi, W. Lutz, S Shuichi. International Cooperative Activities for the Engineering Education between Otto-von-Guericke-University Magdeburg, Germany, and Niigata University, Japan, Journal of Engineering Education Research, 2010, pp. 49-54.

[6] B. Boualem. Principles of Excellence in Engineering Education Applied to GCC/MENA Engineering Colleges and comparison with Australia and France: a thesis with analysis, results, observations, 7th IEEE GCC Conference and Exhibition (GCC), 2013, pp. 547-552.

[7] Y.P. Zhu. Deeply Thinking in Engineering Education Comparing the UK with China, 4th International Conference on Education and Sports Education (ESE), 2013, pp. 82-385.

[8] M. Koichi. Engineering education reform plan created by Prof. Dr. Shimizu and establishment of Nagoya Municipal Science Museum--regarding cooperative education between universities and industries in Japan after the Second World War, Journal of the history of science, Japan, 2014, pp. 97-183.

[9] B. Shao. Study on Applied Undergraduate Education in the Process of Popularization of Higher Education. Dissertation for the Doctoral Degree in Education, Nanjing Normal University, 2009.

[10] J. Lin. Outstanding Engineers' Training for the World, Research in Higher Education of Engineering, 2012, pp. 1-15. 